\title{
Stock Market Volatility and Recent Crises
}

\author{
Xin Tan (Corresponding author) \\ Silberman College of Business, Fairleigh Dickinson University \\ 1000 River Rd, Teaneck, NJ 07666, United States \\ E-mail: xtan@fdu.edu
}

Sorin A. Tuluca

Silberman College of Business, Fairleigh Dickinson University

285 Madison Avenue, Madison, NJ 07940, United States

E-mail: tuluca@fdu.edu

Received: August 12, 2021 Accepted: September 1, 2021 Published: September 10, 2021

doi: 10.5296/ijafr.v11i3.18933

URL: https://doi.org/10.5296/ijafr.v11i3.18933

\begin{abstract}
We study the volatility of the US stock market and its sectors as defined by S\&P before and after four recent crises: the Mexican crises, the Asian crises, the Dotcom crises and the Great Recession. We compare the increase in daily volatility with the increase in the implied daily volatility (derived from the monthly volatility) to determine if there was a lasting economic effect of each crisis or the increase in volatility was due to financial transitory components. We find that for each crisis the effect was different even though the increase in volatility was present for most of the crises in the post crises period. The paper helps investors and economic policy makers understand what the response to each crisis should be to stabilize the economy.
\end{abstract}

Keywords: Financial crises and economic impact, Stock market volatility, S\&P sectors volatility

\section{Introduction}

Stock prices fluctuate over time. Among many studies investigating stock prices and returns, one important stream focuses on the volatility of stock returns (e.g. Barclay, Litzenberger, \& Warner, 1990; Bartram, Brown, \& Stulz, 2012; French \& Roll, 1986; Officer, 1973; Perry, 1982; Schwert, 1989a, 1989b, 1998; Skinner, 1989). In this context, the volatility of stock return is measured by the variance or the standard deviation of returns over a period of time. 


\section{Mll Macrothink}

International Journal of Accounting and Financial Reporting

ISSN 2162-3082

2021, Vol. 11, No. 3

The study of the volatility of stock returns is important for at least two reasons: financial stability and future economic growth. Schwert (1989b) studied more than 150 years of stock market volatility and concluded that such volatility increases during recessions. Schwert (1989b) claimed the increase in volatility is linked to macroeconomic future volatility and thus could be one of the business cycle indicators.

Other earlier studies also indicated that the stock market volatility increased during minor and major crises. For example, Officer (1973) observed greater than expected stock market volatility when economic variability was high in the case of the Great Depression. Schwert (1989a) observed this relation between stock return volatility and macroeconomic variability over time but also noted that unlike the volatility of macroeconomic variables, stock return volatility spiked up during periods of unusual economic variability.

Drawing on the observation that stock return volatility increases during financial crises and on the fact that such increase could be related to either economic variables or possibly to noise, this paper attempts to determine for four different financial crises if the response of the volatility is due to noise or economic fundamentals. While the extant literature findings overwhelmingly agreed that volatility of stock returns increases during a financial crisis (see for example Tuluca and Zwick (2001)), there was less attention paid to the persistence of such increase and even less attention paid to different type of crises and their aftermath volatility. Furthermore, different sectors of the economy would be affected differently by crises and thus an investigation of the effect of crises on the volatility of different economic sectors is of import for both decision makers and investors. The purpose of this paper is then to identify if increases in stock return volatility after a crisis was persistent and thus had fundamental economic effect (as posited for instance by (Schwert, 1989a)) or only temporary financial effects due to noise (as posited for instance by (Black, 1986)).

The rest of paper proceeds as follows: section two presents the existing literature on this subject; section three describes the research methodology and its foundation; section four reports the data; section five discusses the specific findings. The paper concludes with a summary of the study's implication for both researchers and practitioners.

\section{Literature Review}

As indicated earlier, the study of the volatility of stock returns is considered as an important research topic (Aizenman and Pinto, 2004). Some studies were concerned with the nature and sources of the stock returns volatility. For instance, there are studies investigating the impact of public and private information (Barclay et al., 1990; French \& Roll, 1986), and financial derivatives (Grullon, Lyandres, \& Zhdanov, 2012) on the volatility of stock return.

Some studies aimed at differentiating the factors contributing to the volatility of stock returns. For instance, Black (1986) emphasizes the role of noise, namely the larger effects of many small unidentifiable events relative to those of a small number of larger more identifiable ones. Such noise may account for some of the larger than expected stock market volatility when economic variability is high. The increased volatility of returns of U.S. stock prices during crises may result primarily from changes in fundamental determinants of stock prices 
such as expected earnings or interest rates. In line with Black (1986), French and Roll (1986) suggested the increased volatility may reflect the effects of noise in the form of increased uncertainty in financial market behavior, liquidity preference and trading strategies. These studies represent an effort to explain the lackluster performance of efficient market models. The different roles played by fundamental determinants and noises on the volatility of stock returns serve as the theoretical lenses of the present study.

One particular context suitable to study the various aspects of stock return volatility is financial crises. The extant literature shows that stock return volatility during and after financial crises have been studied from various angles. For instance, Danielsson, Valenzuela and Zer (2018) construct a cross-country database spanning up to 211 years and 60 countries to examine the effects of stock market volatility on risk-taking and financial crises. They conclude volatility itself does not predict crises. However, prolonged periods of low volatility have strong in-sample and out-of-sample predictive power over the incidence of banking crises and can be used as a reliable crisis indicator. Kongslip and Mateus (2017) use empirical data to analyze the effect of different idiosyncratic volatility measures in global financial crises. Their findings imply that the idiosyncratic volatility is the best stock return predictor for every sub-period both in Bear and Bull markets. The impact of financial crises on the volatility of stock returns can cross borders, as indicated by Kenourgios (2014). Kenourgios (2014) uses a sample of international implied volatility indices on daily changes to explore explore asymmetric conditional correlation dynamics across stable and crisis periods and across the different phases of the Global Financial Crisis (GFC) and the Eurozone Sovereign Debt Crisis (ESDC). The findings provide evidence for the existence of contagion in cross-market volatilities. A similar study was conducted in the mid-east countries. Charfeddine and Refai (2019) examine the impact of the two recent political and economic crises of March 2014 and June 2017 on the stock market dependence and volatility spillover between Qatar and the other Gulf Cooperation Council (GCC) countries.

Tuluca et al. (2003) are among the first to study the stock return volatility effect on the economy and its sectors during and after a financial crisis. They used only the Asian crises for such purpose. The present study extends that research by examining four different crises: the Mexican tequila crisis of 1994-95, the Asian crisis of 1997-98, the Nasdaq or dot.com-centered US stock market decline in 2000-2002, and the Financial Crisis of 2007-2008. While such question is not new and comparison of crises was done in the past for other geographic regions (see for instance Kaminsky and Reinhart (1998)), this study will shed some light on how different type of crises affect the US economy and its sectors.

\section{Research Methodology}

As discussed in the literature (see (Schwert, 1989a) for an extensive discussion), the stock market volatility could have a fundamental or a purely financial effect on the macroeconomic variables. In the first case the effect is persistent while in the latter the stock market volatility does not affect the economic fundamentals. The research methodology to discriminate between the two is an extension of the idea proposed by French and Roll (1986), who discriminate between persistent stock price changes that arise from fundamental factors and 


\section{Mll Macrothink}

International Journal of Accounting and Financial Reporting

ISSN 2162-3082

2021, Vol. 11, No. 3

temporary or reversible price changes due to "noise" such as trading errors, mispricing, over or under reaction.

Following Perry (1982) and Tuluca et al. (2003), we discriminate between long run and short run effects by comparing daily return variances in the pre- and post-crisis intervals with the daily variances implied by variances for longer holding periods such as a month. Long-term effects should increase longer term or implied daily variances, while short-term effects should not.

In each crisis, we will compute the daily volatility for pre-crisis $\left(\sigma_{\text {pre }}^{d}\right)$ and post-crisis $\left(\sigma_{\text {post }}^{d}\right)$ intervals. We will also compute the monthly volatility for the two periods. Since our discussion is based on ratios of volatilities (see equation (1)), taking the ratios of monthly volatilities is equivalent to taking the ratio of the implied daily variance for pre-crisis $\left(\sigma_{\text {pre }}^{i d}\right)$

and post-crisis $\left(\sigma_{\text {post }}^{i d}\right)$ intervals. If the inequality shown in equation (1) is true, we interpret the effect of the crises as noise in the financial markets as the effect is not supported by an increase in the implied daily volatility or the monthly volatility. In other words, the monthly volatility is lower than what the daily measured volatility would imply. If the inequality is reversed, it can be inferred that the effect of crisis is due to fundamental changes in the economic factors rather than purely financial effects.

$$
\frac{\sigma_{\text {post }}^{d}}{\sigma_{\text {post }}^{i d}} \geq \frac{\sigma_{\text {pre }}^{d}}{\sigma_{\text {pre }}^{i d}}
$$

From (1) we can derive (2) as below. Finally, since the implied daily volatility is computed by dividing the monthly volatility by the square root of the days in a month we can write (3) as the dividing factor will be the same for the pre-crisis and post-crisis measure.

$$
\begin{aligned}
& \frac{\sigma_{\text {post }}^{d}}{\sigma_{\text {pre }}^{d}} \geq \frac{\sigma_{\text {post }}^{i d}}{\sigma_{\text {pre }}^{i d}} \\
& \frac{\sigma_{\text {post }}^{d}}{\sigma_{\text {pre }}^{d}} \geq \frac{\sigma_{\text {post }}^{m}}{\sigma_{\text {pre }}^{m}}
\end{aligned}
$$

As a result of the above transformations, we construct the TEST variable as in (4). If the TEST variable is less than 1, it will indicate as explained in above that the crisis effect was a noisy and transitory behavior of the equity markets. If it is greater than 1 , the crisis produced more lasting changes in the economic fundamentals.

$$
\mathrm{TEST}=\frac{\sigma_{\text {post }}^{m}}{\sigma_{\text {pre }}^{m}} / \frac{\sigma_{\text {post }}^{d}}{\sigma_{\text {pre }}^{d}}
$$

\section{Data}

In analyzing effects on stock price volatility in the U.S. we looked both at the overall stock market as represented by S\&P 500 and prices for sectors of the economy as represented in the 


\section{Macrothink}

International Journal of Accounting and Financial Reporting

ISSN 2162-3082

S\&P 500 index. All data for the S\&P500, where industry sectors are energy (ENER), materials (MATS), industrials (INDS), consumer discretionary CNDS), consumer staples (CNST), health care (HC), financial (FIN), retail (RETL), information technology (IT), telecommunications (TELC), and utilities (UTIL) are obtained from Bloomberg terminals.

For each crisis, we first identify pre-crisis and post-crisis intervals based on literature and events in that period. We allow pre and post crises of some considerable length to capture the persistence if any in volatility.

The pre-crisis and post-crisis intervals for the four crises are identified as follows:

\subsection{Mexican Crisis}

The Mexican Crisis was triggered by expansionary policy during the 1994 presidential election (Whitt Jr, 1996). The Peso was devalued in December 1994. This suggests the pre-crisis interval should end no later than mid-1994. The $\$ 50$ billion Mexican bailout occurred in January 1995. Mexico was able to borrow $\$ 8$ billion in the second half of 1995 and the peso achieved an acceptable degree of stability by March 1995. However, the Mexican economy fell 6.5\% in 1995 (Edwards, 1997). In this study, we use May 1992 through April 1994 as the pre-crisis interval and May 1995 through April 1997 as the post-crisis period.

\subsection{Asian Crisis}

The financial crisis began when the Thai baht was devalued in July 1997 (Mishkin, 1999). Between July and December 1997, the crisis spread to Indonesia, Malaysia, and South Korea. International banks agreed to a restructuring of Korean debt in January 1998. Indonesia and the IMF reached a third restructuring package in April 1998 and a final package in June 1998. We use June 1995 through May 1997 as a pre-crisis interval and June 1998 through May 2000 as a post crisis period.

\subsection{Dot-com Bubble Burst}

The Dot-Com bubble occurred in stages. The first phase was largely Dot-Com Bubble which referrers to the grossly overvalued stock market in late-1990s (DeLong \& Magin, 2006). The Nasdaq peaked at 5132 on March 10, 2000, and fell to 2500 by the end of the year. Meanwhile, the Dow peaked around 11,000 in 1999 and fell only to 10,500 during 2000 and only to 9600 just before $9 / 11$. The post $9 / 11$ phase was broader based. Between $9 / 11$ and February 2003, the Dow fell $20 \%$ to 8,100 and the Nasdaq fell to 1300 . If the focus is on Dot-Com bubble, the pre-crisis interval ends sometime before March 2000. If the focus is more broad-based, the crisis did not really take hold fully until after 9/11. We use March 1998 through February 2000 as the pre-crisis interval and December 2002 through November 2004 as the post crisis interval.

\subsection{Financial Crisis}

The greatest financial crisis since the Great Depression began sometime in 2007 The first notable event of the crisis occurred on March 4, when HSBC announced greater than 


\section{MlMacrothink}

International Journal of Accounting and Financial Reporting ISSN 2162-3082 2021, Vol. 11, No. 3

expected delinquencies of one of its portfolios of mortgage-backed securities. On April 22, New Century Financial declared bankruptcy. On June 22, Bear Stearns pledged a collateralized loan to one of its hedge funds but did not support another. This suggests the pre-crisis sometime between March and June of 2007. We use June 2005 through November 2007 as the pre-crisis interval.

For the post crisis interval, a starting point in the spring of 2009 is suggested when the major US banks under pressure from Treasury Secretary Geithner successfully issued new stock. A possible complication is that the Europeans were beginning to have their own problems at that point. For the financial crisis, we chose the interval from June 2009 through November 2011 as the post-crisis interval.

\section{Results and Analysis}

Our results are presented in four tables: MEXICO, ASIA, DOTCOM, and GREAT RECESSION. In each of the four tables, the upper rows the standard deviation of monthly returns dividend in the pre and post crises intervals. We construct RM as the left term of equation (3). We also present the $\mathrm{F}$ test for the equality of the variance and its $95 \%$ significance value. The lower rows of the tables show the same standard deviations and ratios for the actual daily variances with the RD being the right term of equation (3).

The TEST row at the bottom of each table is the result of equation (4). As discussed before, a TEST greater than 1 indicate long term effects on fundamental economic variables while TEST equal to or less than 1 suggest that any effects of the crisis on were transitory disturbances representing noise in the equity markets.

Table 1. MEXICO

\begin{tabular}{|c|c|c|c|c|c|c|c|c|c|c|c|c|}
\hline & SP500 & ENER & MATS & INDS & CNDS & CNST & $\mathrm{HC}$ & FIN & RETL & IT & TELC & UTIL \\
\hline \multicolumn{13}{|l|}{ Monthly volatility } \\
\hline Pre-crisis std (\%) & 2.19 & 3.22 & 2.98 & 2.56 & 3.24 & 3.28 & 4.41 & 3.59 & 3.85 & 4.23 & 3.52 & 3.24 \\
\hline Post-crisis std (\%) & 2.95 & 3.16 & 3.57 & 2.98 & 3.30 & 3.28 & 4.49 & 4.28 & 4.67 & 6.37 & 4.00 & 3.25 \\
\hline RM & 1.35 & 0.98 & 1.20 & 1.16 & 1.02 & 1.00 & 1.02 & 1.19 & 1.21 & 1.51 & 1.14 & 1.00 \\
\hline $\mathrm{F} \quad(.05=>1.98)$ & 1.81 & 1.04 & 1.43 & 1.36 & 1.04 & 1.00 & 1.04 & 1.42 & 1.47 & $2.28 *$ & 1.29 & 1.01 \\
\hline \multicolumn{13}{|l|}{ Daily Volatility } \\
\hline Pre-crisis std (\%) & 0.57 & 0.84 & 0.75 & 0.61 & 0.79 & 0.74 & 1.20 & 0.84 & 0.94 & 1.22 & 0.78 & 0.62 \\
\hline Post-crisis std (\%) & 0.72 & 0.90 & 0.76 & 0.76 & 0.78 & 0.81 & 1.04 & 1.04 & 1.01 & 1.64 & 1.03 & 0.64 \\
\hline $\mathrm{RD}$ & 1.26 & 1.07 & 1.02 & 1.24 & 0.99 & 1.09 & 0.86 & 1.24 & 1.07 & 1.34 & 1.31 & 1.04 \\
\hline $\mathrm{F} \quad(.05 \Rightarrow>1.15)$ & $1.58 *$ & $1.15^{*}$ & 1.03 & $1.55^{*}$ & 1.02 & $1.20 *$ & $1.34^{*}$ & $1.54 *$ & $1.15^{*}$ & $1.79 *$ & $1.73 *$ & 1.09 \\
\hline Test & 1.07 & 0.92 & 1.18 & 0.94 & 1.03 & 0.91 & 1.18 & 0.96 & 1.13 & 1.13 & 0.87 & 0.96 \\
\hline
\end{tabular}

*Significant at $5 \%$

For MEXICO (1994-95), the TEST statistic for the overall market (SP500) of 1.07, or slightly more than one, suggests that the increase in longer term variances from pre to post was most likely due to fundamental effects. However, the F statistic for the monthly change is weak and thus one cannot conclude that the monthly volatility was different pre post crises. 


\section{$\triangle$ Macrothink}

International Journal of Accounting and Financial Reporting ISSN 2162-3082 2021, Vol. 11, No. 3

While the F statistic for the daily volatility is higher than the critical value since the TEST is very close to one, we can conclude that there was a mild fundamental effect post this crisis. Except for IT where both F values are higher than the critical one and thus one can conclude that there was some noise at work the results suggests little change in terms of the behavior of daily variance vis-a vis of the monthly (implied daily) variance. The IT "noise" can be a prelude to the dot com bubble that will be discussed later.

Table 2. ASIA

\begin{tabular}{lcccccccccccc}
\hline & SP500 & ENER & MATS & INDS & CNDS & CNST & HC & FIN & RETL & IT & TELC & UTIL \\
\hline Monthly volatility & & & & & & & & & & & \\
\hline Pre-crisis std (\%) & 3.04 & 3.29 & 3.68 & 3.16 & 3.30 & 3.30 & 4.54 & 4.18 & 4.72 & 6.47 & 4.09 & 3.08 \\
\hline Post-crisis std (\%) & 5.55 & 6.68 & 7.91 & 6.14 & 6.74 & 6.15 & 6.67 & 8.93 & 7.57 & 9.81 & 6.96 & 5.04 \\
\hline RM & 1.83 & 2.03 & 2.15 & 1.94 & 2.05 & 1.86 & 1.47 & 2.13 & 1.60 & 1.51 & 1.70 & 1.63 \\
\hline F $(.05=>1.98)$ & $3.34^{*}$ & $4.11^{*}$ & $4.63^{*}$ & $3.78^{*}$ & $4.18^{*}$ & $3.48^{*}$ & $2.16^{*}$ & $4.55^{*}$ & $2.57^{*}$ & $2.30^{*}$ & $2.90^{*}$ & $2.67^{*}$ \\
\hline Daily volatility & & & & & & & & & & & & \\
\hline Pre-crisis std (\%) & 0.74 & 0.90 & 0.77 & 0.77 & 0.78 & 0.82 & 1.05 & 1.07 & 0.99 & 1.65 & 1.04 & 0.65 \\
\hline Post-crisis std $(\%)$ & 1.37 & 1.69 & 1.58 & 1.41 & 1.57 & 1.43 & 1.73 & 2.01 & 1.98 & 2.35 & 1.67 & 1.09 \\
\hline RD & 1.86 & 1.87 & 2.05 & 1.83 & 2.02 & 1.73 & 1.65 & 1.87 & 1.99 & 1.43 & 1.62 & 1.68 \\
\hline F $(.05=>1.15)$ & $3.46^{*}$ & $3.50^{*}$ & $4.21 *$ & $3.36^{*}$ & $4.06^{*}$ & $2.99 *$ & $2.72 *$ & $3.51^{*}$ & $3.97 *$ & $2.04 *$ & $2.61 *$ & $2.83^{*}$ \\
\hline Test & 0.98 & 1.08 & 1.05 & 1.06 & 1.01 & 1.08 & 0.89 & 1.14 & 0.81 & 1.06 & 1.05 & 0.97 \\
\hline
\end{tabular}

*Significant at 5\%

The results are similar for ASIA (1997-98), where the TEST statistic of .96 for the market as a whole is slightly less than one. TEST for the other sectors are also around 1, with the financial sector TEST of 1.14 being the largest. The retail sector is the lowest at .86. However, in all the cases the post crises volatility both daily and monthly are significantly higher than those pre crises. This could be possibly explained by the "good volatility" that Bartram et al. (2012) suggest that is possible for US economic sectors. The financial sector certainly had fundamental effects post the Asian crises while the retail sector dependent on the Asian production for many items suffered a noisy increase in volatility based on the possible speculation in the future of the retail companies and the uncertainly of the Asian producer recovery.

Table 3. DOTCOM

\begin{tabular}{lcccccccccccc}
\hline & SP500 & ENER & MATS & INDS & CNDS & CNST & HC & FIN & RETL & IT & TELC & UTIL \\
\hline Monthly volatility & & & & & & & & & & & \\
\hline Pre-crisis std (\%) & 5.26 & 6.28 & 7.75 & 5.77 & 6.39 & 5.89 & 6.43 & 8.17 & 7.16 & 9.10 & 6.45 & 4.92 \\
\hline Post-crisis std (\%) & 3.09 & 3.87 & 4.79 & 3.66 & 4.26 & 2.62 & 2.88 & 3.79 & 4.33 & 5.65 & 4.86 & 3.90 \\
\hline RM & 0.59 & 0.62 & 0.62 & 0.63 & 0.67 & 0.45 & 0.45 & 0.46 & 0.60 & 0.62 & 0.75 & 0.79 \\
\hline F $\quad(.05=>1.98)$ & $2.89^{*}$ & $2.64^{*}$ & $2.62^{*}$ & $2.49^{*}$ & $2.25^{*}$ & $5.04^{*}$ & $4.98^{*}$ & $4.66^{*}$ & $2.73^{*}$ & $2.59^{*}$ & 1.76 & 1.59 \\
\hline Daily Volatility & & & & & & & & & & & & \\
\hline Pre-crisis std $(\%)$ & 1.25 & 1.60 & 1.42 & 1.28 & 1.45 & 1.19 & 1.59 & 1.84 & 1.78 & 2.09 & 1.55 & 0.99 \\
\hline Post-crisis std $(\%)$ & 0.93 & 1.02 & 1.15 & 0.99 & 1.12 & 0.75 & 0.96 & 1.05 & 1.12 & 1.51 & 1.40 & 0.90 \\
\hline
\end{tabular}




\begin{tabular}{lcccccccccccc}
\hline RD & 0.74 & 0.63 & 0.81 & 0.78 & 0.77 & 0.63 & 0.60 & 0.57 & 0.63 & 0.72 & 0.90 & 0.91 \\
\hline $\mathrm{F}(.05=>1.15)$ & $1.80 *$ & $2.48^{*}$ & $1.52 *$ & $1.66^{*}$ & $1.69 *$ & $2.51 *$ & $2.76^{*}$ & $3.10^{*}$ & $2.55^{*}$ & $1.91 *$ & $1.22 *$ & $1.21 *$ \\
\hline Test & 0.79 & 0.97 & 0.76 & 0.82 & 0.87 & 0.70 & 0.74 & 0.82 & 0.97 & 0.86 & 0.83 & 0.87 \\
\hline
\end{tabular}

*Significant at $5 \%$

For DOTCOM (2001-2002), the absence of long-term fundamental effects appears to be very strong. The S\&P500 as proxy for the US market, TEST statistic is .79, and none of the eleven sector TEST statistics is greater than one. This can be easily explained as the dotcom bubble was just NASDAQ companies' phenomenon and did not affect the structure of the economy.

Table 4. GREAT RECESSION

\begin{tabular}{|c|c|c|c|c|c|c|c|c|c|c|c|c|}
\hline & SP500 & ENER & MATS & INDS & CNDS & CNST & $\mathrm{HC}$ & FIN & RETL & IT & TELC & UTIL \\
\hline \multicolumn{13}{|l|}{ Monthly volatility } \\
\hline Pre-crisis std (\%) & 2.22 & 5.05 & 3.49 & 2.67 & 3.12 & 1.77 & 2.58 & 3.26 & 3.15 & 3.97 & 3.72 & 3.24 \\
\hline Post-crisis std (\%) & 4.77 & 6.55 & 7.52 & 6.41 & 5.47 & 2.98 & 3.80 & 6.60 & 4.65 & 5.56 & 4.25 & 3.02 \\
\hline $\mathrm{RM}$ & 2.15 & 1.30 & 2.16 & 2.41 & 1.75 & 1.68 & 1.47 & 2.03 & 1.48 & 1.40 & 1.14 & 0.93 \\
\hline $\mathrm{F} \quad(.05=>1.98)$ & $4.62 *$ & $1.69 *$ & $4.65^{*}$ & $5.79 *$ & $3.07 *$ & $2.84 *$ & $2.17 *$ & $4.10^{*}$ & $2.18^{*}$ & $1.97 *$ & 1.30 & 1.15 \\
\hline \multicolumn{13}{|l|}{ Daily Volatility } \\
\hline Pre-crisis std (\%) & 0.78 & 1.45 & 1.15 & 0.83 & 0.88 & 0.62 & 0.69 & 1.04 & 0.99 & 0.98 & 0.92 & 0.95 \\
\hline Post-crisis std (\%) & 1.27 & 1.65 & 1.72 & 1.52 & 1.39 & 0.82 & 1.05 & 1.93 & 1.14 & 1.33 & 1.04 & 1.01 \\
\hline $\mathrm{RD}$ & 1.63 & 1.13 & 1.50 & 1.82 & 1.58 & 1.32 & 1.52 & 1.86 & 1.15 & 1.36 & 1.13 & 1.06 \\
\hline $\mathrm{F} \quad(.05=>1.15)$ & $2.65 *$ & $1.28 *$ & $2.25 *$ & $3.32 *$ & $2.48 *$ & $1.75^{*}$ & $2.31 *$ & $3.46^{*}$ & $1.33 *$ & $1.86^{*}$ & $1.28 *$ & 1.12 \\
\hline Test & 1.32 & 1.15 & 1.44 & 1.32 & 1.11 & 1.27 & 0.97 & 1.09 & 1.28 & 1.03 & 1.01 & 0.88 \\
\hline
\end{tabular}

*Significant at $5 \%$

The major exception is FINANCIAL CRISIS (2008). For this crisis, the TEST of 1.32 suggests fundamental effects on stock price volatility. The contrast between this evidence of a fundamental effect and their absence for the three earlier crises is broadly consistent with the contrasting economic patterns for the four crises. For the Mexican and Asian crises, real GDP in the US continued to grow at or above long-term trends in 1995 and again in 1998. In the dotcom crisis, real growth fell at a $2 \%$ rate in the first and third quarters of 2001 but was down only slightly for the year as a whole. On the other hand, in late 2008 and early 2006, the economy fell at an $6 \%$ annual rate and the unemployment rate rose from less than $5 \%$ in the fall of 2008 to more than $10 \%$ in the spring of 2009.

Perhaps even more striking is that the largest evidence of fundamental or economic effects in the 2008 crisis occur in the two most cyclically sensitive sectors, materials (TEST of 1.44) and industrials (TEST of 1.32). Consumer non disposable spending and Retail were also fundamentally affected. And the smallest TEST occurs for two of the least cyclical industries - health care with TEST of .97 and utilities with TEST of .88, in both cases appearing that the effects were transitory due to financial markets fluctuation. 


\section{Mll Macrothink \\ International Journal of Accounting and Financial Reporting \\ ISSN 2162-3082 \\ 2021, Vol. 11, No. 3}

\section{Conclusion}

Schwert (1989b) and Officer (1973) observed the expected relation between economic and stock price volatility over time but that stock price volatility spiked up during intervals of high economic volatility. Black (1986), as well as French and Roll (1986), suggested that some of this higher than easily explained rise in stock market volatility may result from noise such as increased uncertainty in financial market behavior, liquidity preference and trading strategies. To enhance our understanding of increased stock price volatility during economic and financial crises, this paper examined four intervals of economic and financial crisis to determine if the increased volatility following these crises was fundamental or purely financial. We found evidence of fundamental effects in the crisis of 2008, when the economy fell sharply, and "noise" effects in the dotcom bubble but almost no effects in the other two crises when economic variability was much smaller for the US.

As discussed in Aizenman and Pinto (2004), understanding volatility and its effect on economy is central for decision making, fiscal and monetary policy and investors. Therefore, this paper is a step in the direction of understanding what the response to different type of crises should be and how investors should process the information.

\section{References}

Aizenman, J., \& Pinto, B. (2004). Managing volatility and crises: a practitioner's guide overview. National Bureau of Economic Research.

Barclay, M. J., Litzenberger, R. H., \& Warner, J. B. (1990). Private information, trading volume, and stock-return variances. The Review of Financial Studies, 3(2), 233-253.

Bartram, S. M., Brown, G., \& Stulz, R. M. (2012). Why are US stocks more volatile?. The Journal of Finance, 67(4), 1329-1370.

Black, F.. (1986). Noise. The Journal of Finance, 41(3), 528-543.

Charfeddine, L., \& Al Refai, H. (2019). Political tensions, stock market dependence and volatility spillover: Evidence from the recent intra-GCC crises. The North American Journal of Economics and Finance, 50, 101032.

Danielsson, J., Valenzuela, M., \& Zer, I. (2018). Learning from history: Volatility and financial crises. The Review of Financial Studies, 31(7), 2774-2805.

DeLong, J. B., \& Magin, K. (2006). A short note on the size of the dot-com bubble. National Bureau of Economic Research.

Edwards, S. (1997). The Mexican peso crisis? How much did we know? When did we know it?. National Bureau of Economic Research.

French, K. R., \& Roll, R. (1986). Stock return variances: The arrival of information and the reaction of traders. Journal of Financial Economics, 17(1), 5-26.

Grullon, G., Lyandres, E., \& Zhdanov, A. (2012). Real options, volatility, and stock returns. The Journal of Finance, 67(4), 1499-1537. 


\section{Mll Macrothink}

International Journal of Accounting and Financial Reporting

ISSN 2162-3082 2021, Vol. 11, No. 3

Kaminsky, G. L., \& Reinhart, C. M. (1998). Financial crises in Asia and Latin America: Then and now. The American Economic Review, 88(2), 444-448.

Kenourgios, D. (2014). On financial contagion and implied market volatility. International Review of Financial Analysis, 34, 21-30.

Kongsilp, W., \& Mateus, C. (2017). Volatility risk and stock return predictability on global financial crises. China Finance Review International, 7(10), 33-66.

Mishkin, F. S. (1999). Lessons from the Asian crisis. Journal of International Money and Finance, 18(4), 709-723.

Officer, R. R. (1973). The variability of the market factor of the New York Stock Exchange. the Journal of Business, 46(3), 434-453.

Perry, P. R. (1982). The Time-Variance Relationship of Security Returns: Implications for the Return-Generating Stochastic Process. The Journal of Finance, 37(3), 857-870.

Schwert, G. W. (1989a). Business Cycles, Financial Crises and Stock Volatility. NBER Working Paper(2957).

Schwert, G. W. (1989b). Why does stock market volatility change over time?. The Journal of Finance, 44(5), 1115-1153.

Schwert, G. W. (1998). Stock market volatility: Ten years after the crash. National Bureau of Economic Research.

Skinner, D. J. (1989). Options markets and stock return volatility. Journal of Financial Economics, 23(1), 61-78.

Tuluca, S. A., \& Zwick, B. (2001). The effects of the Asian crisis on global equity markets. Financial Review, 36(1), 125-142.

Tuluca, S. A., Zwick, B., \& Seiler, M. J. (2003). International versus US sector diversification strategies in the wake of the Asian crisis. American Business Review, 21(1), 67.

Whitt Jr, J. A. (1996). The Mexican peso crisis. Economic Review-Federal Reserve Bank of Atlanta, 81(1), 1.

\section{Copyright Disclaimer}

Copyright for this article is retained by the author(s), with first publication rights granted to the journal.

This is an open-access article distributed under the terms and conditions of the Creative Commons Attribution license (http://creativecommons.org/licenses/by/4.0/) 